\title{
Modeling Approach for Determining Equivalent Optical Constants of Plastic Shading Nets under Solar Radiation Conditions
}

\author{
A. M. Abdel-Ghany ${ }^{1,2}$ and I. M. Al-Helal ${ }^{1}$ \\ ${ }^{1}$ Department of Agricultural Engineering, College of Food and Agriculture Sciences, King Saud University, P.O. Box 2460, \\ Riyadh 11451, Saudi Arabia \\ ${ }^{2}$ Mechanical Power Engineering Department, Faculty of Energy Engineering, South Valley University, Aswan 81528, Egypt
}

Correspondence should be addressed to A. M. Abdel-Ghany, aghany@ksu.edu.sa

Received 16 February 2012; Accepted 3 August 2012

Academic Editor: Fengqiang Sun

Copyright ( 2012 A. M. Abdel-Ghany and I. M. Al-Helal. This is an open access article distributed under the Creative Commons Attribution License, which permits unrestricted use, distribution, and reproduction in any medium, provided the original work is properly cited.

The radiative properties of several plastic shading nets were measured under natural solar radiation conditions. We found that the plastic nets behave as homogeneous translucent materials (e.g., plastic film, plastic sheets, and glass). Based on this behavior, we suggest that it is possible to treat plastic nets as translucent materials and to characterize them with equivalent optical constants (i.e., equivalent refractive indexes, $n_{\mathrm{eq}}$, and equivalent extinction coefficients, $\sigma_{\mathrm{eq}}$ ). Here a physical model to determine $n_{\mathrm{eq}}$ and $\sigma_{\mathrm{eq}}$ of plastic nets was described in analogy to homogeneous translucent materials. We examined three groups of nets based on their color (black, black-green, and beige). Each group consisted of nets with four or five different porosities. Nets of each group had almost the same texture structure. For each group, we derived an equation for $n_{\mathrm{eq}}$ as a function of the net porosity and determined an average value for $\sigma_{\mathrm{eq}}$. Once values of $n_{\mathrm{eq}}$ and $\sigma_{\mathrm{eq}}$ were determined, the solar radiative properties of a net could then be calculated from $n_{\mathrm{eq}}$ and $\sigma_{\mathrm{eq}}$ for any incident angle of solar beam radiation without the need of measurements. The present model was validated by comparing the calculated with the measured radiative properties of three nets at different incident angle of solar beam radiation. The calculated radiative properties reasonably agreed with measured values.

\section{Introduction}

During the last decade, the use of plastic nets for shading agricultural industrial and residential structures in hot and sunny regions has steadily expanded because plastic nets offer many economical and environmental benefits [1-4]. These include (i) reduction or elimination of energy consumption used for heating or cooling structures, (ii) reduction of crop transpiration as well as water consumption for irrigation in agriculture structures in arid regions, and (iii) improvement in environmental and human-health conditions by reducing the need for pesticides. The diffusive nature of the net threads causes the incident beam radiation to be scattered forward (specularly and diffusively) during transmission [5]. This provides a uniform radiation distribution inside structures covered with nets to add more advantages to plastic nets applications. Various types of plastic nets with different colors and different shading powers are popular in the markets and are used for many purposes in many parts of the world. Commercial nets are usually defined by the following (i) the net porosity $(\phi)$, that is, the surface empty area (uncovered by the plastic threads) divided by the total surface area of the net. The value of $\phi$ is usually determined by image processing or solar radiation transmission [6]. (ii) The shading factor (SF), defined as the percentage of global solar radiation that the net is able to block. SF strongly depends on the incident angle of the beam radiation $(\theta)$, and to estimate the value of SF for a net correctly, the directional solar radiative properties ( $\theta$ dependence) of the net should be determined. Accordingly, the directional solar radiative properties of nets are essentially needed to characterize different types of plastic nets according to their shading power. However, little information about how to determine these properties is available in the literature. 
Some research groups have investigated the radiative properties of different types of plastic net or total net-covered structure models in laboratories under artificial lighting [2$4,7]$. In order to replace expensive measuring techniques in laboratories, we developed a simple method for measuring the radiative properties of nets under natural conditions of global, diffuse, and direct beam solar radiation, and under natural conditions of the photosynthetically active radiation (PAR) $[8,9]$. The method was used to test nets with different colors, porosities, and texture structures. Even though, nets are three-dimensional, nonhomogeneous, and porous materials, the behaviors of the plastic nets under solar radiation conditions were found to be similar to those of translucent homogeneous materials (e.g., plastic films, glass and rigid plastic sheets such as polycarbonate and acrylic) $[8,9]$. In other words, the changes in the global, diffuse, and direct beam transmittances and reflectances of nets with the incident angle $(\theta)$ were similar to those of different translucent materials that were measured under natural conditions of solar radiation [10-14]. This makes it possible to determine optical constants, in analogy to homogeneous transparent materials, to be used for calculating the radiative properties of nets. This is because calculation methods are preferable and easier than the measuring methods which are quite difficult and prohibitively expensive. Accordingly, the goal of the present study was to develop a theoretical model to investigate equivalent optical constants (i.e., equivalent refractive indexes and equivalent extinction coefficients) for plastic nets in analogy to homogeneous translucent materials. Three groups of nets (i.e., a black group, beige group, and black-green group) were selected to develop the model.

\section{Materials and Methods}

2.1. The Plastic Net Materials. The nets selected for testing were classified into three groups. Nets in each group have the same color, same texture structure, and different porosities $(\phi)$. The nets were locally produced by Saudi companies. Samples of the nets $(5 \mathrm{~cm} \times 5 \mathrm{~cm})$ were scanned at a resolution of $4800 \mathrm{dpi}$ with a flatbed scanner (HP-5590). Photos of the scanned nets were magnified several times and converted into high-contrast black (thread projection area) and white (empty area) colors using Adobe Photoshop software. The resulting photos showed the net threads as black on a white background. The porosity (the empty area divided by the total surface area of the net, $\phi$ ) of each net was estimated. The three groups were the black group having porosities $\phi$ of $0.30,0.36,0.43,0.54$, and 0.64 ; the beige group having porosities $\phi$ of $0.32,0.34,0.36$, and 0.45 ; the black-green group having porosities $\phi$ of $0.45,0.46,0.48$, 0.50 , and 0.51 . In the latter group, the texture was interlaced threads made of black and green plastic robs knitted together. Photos of the tested nets (one from each group) are shown in Figure 1.

2.2. The Equivalent Optical Constants Model. In the case of homogeneous translucent materials (e.g., plastic films, plastic sheets, or glass), the measured radiative properties (reflectance, transmittance, and absorptance) are referred to as effective properties. This is because the incident beam over the material surface suffers an infinite number of multiple internal reflections inside the material itself (Figure 2). With each internal reflection, there are transmitted and reflected portions below and above the material surfaces. The summation of the reflected components above the material surface is the effective reflectance and of those below the material surface is the effective transmittance; both can be measured using radiation sensors. According to [5], transmission of direct beam radiation through a plastic net was characterized as (i) the unscattered beam that is transmitted through the net pores, (ii) the beam that is reflected forward on the thread surfaces specularly, and (iii) the beam that is diffused during transmission. On the other hand, the reflected beam will be a combination of specularly reflected beam, and backward scattered beam. For several types of nets (having different colors, porosities, and texture structures) tested in [5], the forward diffused beam was less than $20 \%$ of the incident beam radiation. For the modeling approach, the unscattered beam, the specularly reflected (forward or backward) beam and the diffused beam were assumed to have the same characteristic manner and were considered as direct beams transmitted or reflected from the net. In analogy to homogeneous materials, the effective transmittance and reflectance of a plastic net to the direct beam solar radiation $\left(\tau_{r}\right.$ and $\left.\rho_{r}\right)$ can be expressed as [15] by

$$
\tau_{r}=\frac{\tau^{*}\left(1-\rho^{*}\right)}{1-\left(\tau^{*} \rho^{*}\right)^{2}}, \quad \rho_{r}=\rho^{*}\left(1+\tau^{*} \tau_{r}\right),
$$

where $\tau^{*}$ is the transmittance of the beam radiation due to absorption only in the net material with a porosity $\phi$ and a solid matrix of $(1-\phi) ; \rho^{*}$ is the interface reflectance between the net surface and air.

By eliminating $\rho^{*}$ from (1) a second-order algebraic equation with the unknown $\tau^{*}$ can be obtained. By solving the roots of this equation, the value of $\tau^{*}$ is given by [15] as

$$
\tau^{*}=\left\{\frac{\tau_{r}^{2}-\left(1-\rho_{r}\right)^{2}}{2 \tau_{r}}\right\} \pm\left\{\left(\frac{\tau_{r}^{2}-\left(1-\rho_{r}\right)^{2}}{2 \tau_{r}}\right)^{2}+1\right\}^{1 / 2} .
$$

Reasonable (i.e., positive) values for $\tau^{*}$ are obtained by considering the plus sign of (2). The input parameters to (1) and (2) are the transmittance and reflectance of the net to direct beam radiation $\left(\tau_{r}\right.$ and $\left.\rho_{r}\right)$ that can be measured using a pyranometer underneath the net and an albedometer above the net. The value of $\rho^{*}$ is obtained from the direct substitution of $\tau^{*}$ in (1). Once values of $\tau^{*}$ and $\rho^{*}$ were determined one time (e.g., at normal incidence), the equivalent optical constants $\left(n_{\mathrm{eq}}\right.$ and $\sigma_{\text {eq }}$ ) of the plastic net can be determined, in analogy to homogeneous translucent materials, as follows.

The interface reflectance $\rho^{*}$ at normal incidence between the air $(n=1)$ and the net surface having the equivalent refractive index $\left(n_{\mathrm{eq}}\right)$ is given by

$$
\rho^{*}=\frac{\left(n_{\mathrm{eq}}-1\right)^{2}}{\left(n_{\mathrm{eq}}+1\right)^{2}} .
$$




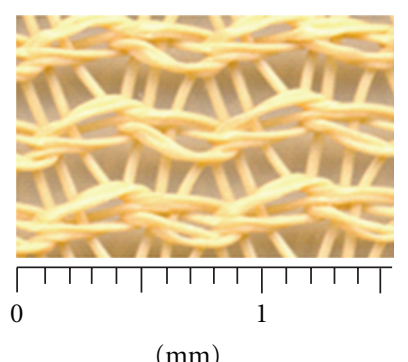

Image of a beige net

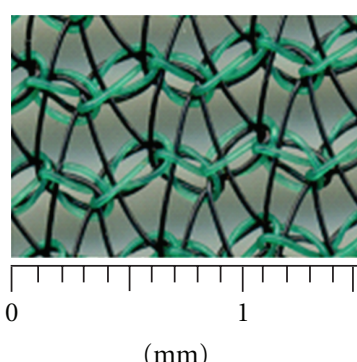

Image of a black-green net

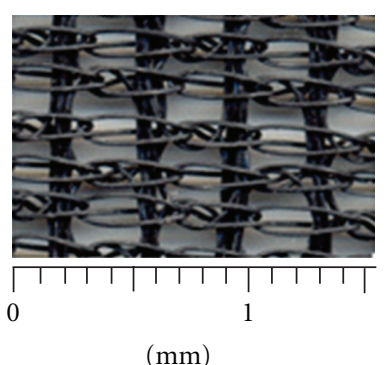

$(\mathrm{mm})$

Image of a black net

Figure 1: Scanner images of a net in each group tested in this study.

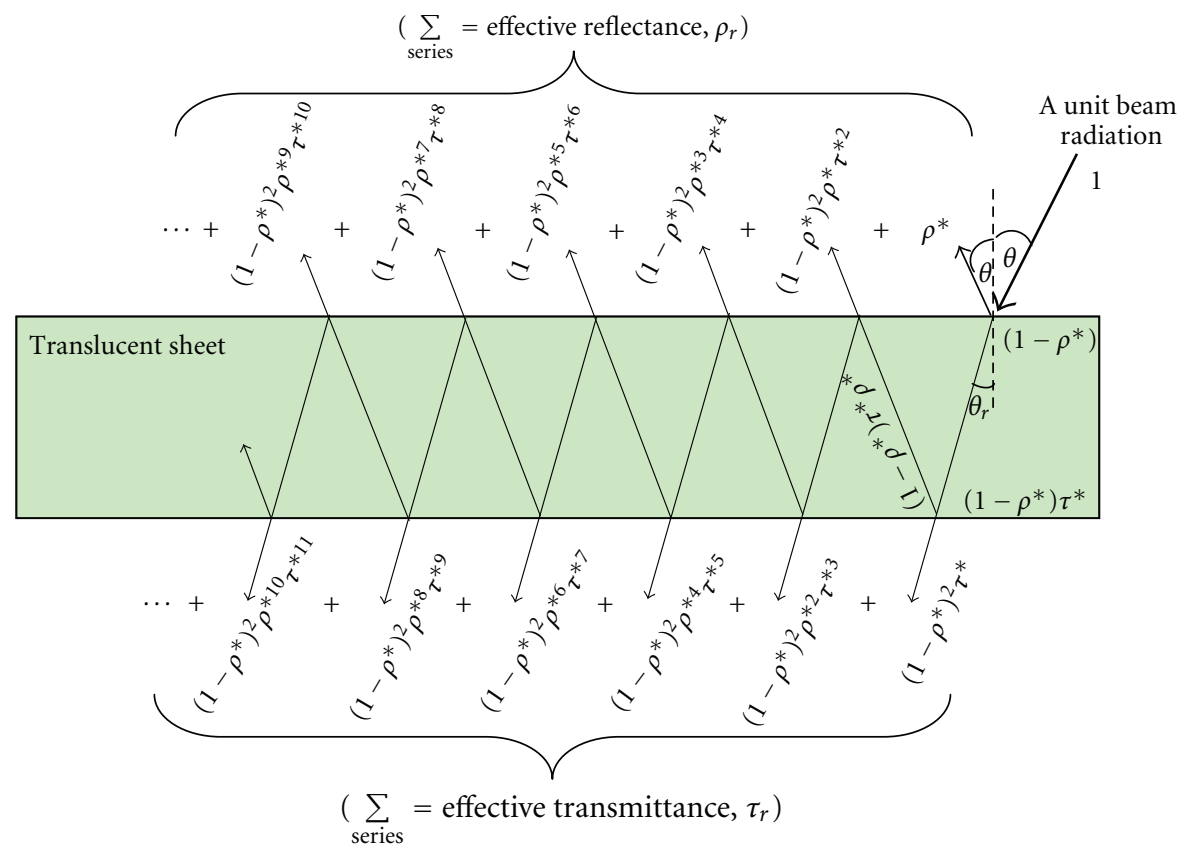

FIGURE 2: Tracing of a unit beam radiation through a translucent sheet to illustrate the concept of the effective reflectance and effective transmittance of the sheet.

Also at normal incidence, the transmittance due to absorption $\left(\tau^{*}\right)$ and the equivalent absorption coefficient $\left(\sigma_{\mathrm{eq}}\right)$ of the net material can be expressed in similar manner of the homogeneous translucent films by replacing the film thickness with the net density or net solidity $(1-\phi), \phi$ is the net porosity. Thus, the relation between $\tau^{*}$ and $\sigma_{\text {eq }}$ is given by

$$
\tau^{*}=\operatorname{Exp}\left\{-\sigma_{\mathrm{eq}}(1-\phi)\right\} .
$$

In $(4), \sigma_{\mathrm{eq}}$ is dimensionless whereas the unit of the absorption coefficient of a homogeneous translucent sheet is $\mathrm{mm}^{-1}$ if the sheet thickness is in $\mathrm{mm}$.

Once the values of the equivalent optical constants $\left(\sigma_{\mathrm{eq}}\right.$ and $n_{\mathrm{eq}}$ ) are determined for a net, the directional radiative properties of this net can be calculated at any incidence angle $(\theta)$ of the beam radiation. In this case, the directional interface reflectance $\left(\rho_{\theta}^{*}\right)$ between the net surface and air is given by $[12,13]$ as

$$
\begin{gathered}
\rho_{\theta}^{*}=\frac{1}{2}\left\{\frac{\sin ^{2}\left(\theta-\theta_{r}\right)}{\sin ^{2}\left(\theta+\theta_{r}\right)}+\frac{\tan ^{2}\left(\theta-\theta_{r}\right)}{\tan ^{2}\left(\theta+\theta_{r}\right)}\right\}, \\
\theta_{r}=\sin ^{-1}\left(\frac{\sin \theta}{n_{\mathrm{eq}}}\right),
\end{gathered}
$$

where $\theta_{r}$ is the equivalent angle of refraction for a beam radiation penetrates through the net. The directional transmittance due to absorption $\left(\tau_{\theta}^{*}\right)$ is given by

$$
\tau_{\theta}^{*}=\operatorname{Exp}\left\{\frac{-\sigma_{\mathrm{eq}}(1-\phi)}{\cos \theta_{r}}\right\} .
$$

The directional radiative properties, with respect to the direct beam radiation, of a plastic net can be obtained by 


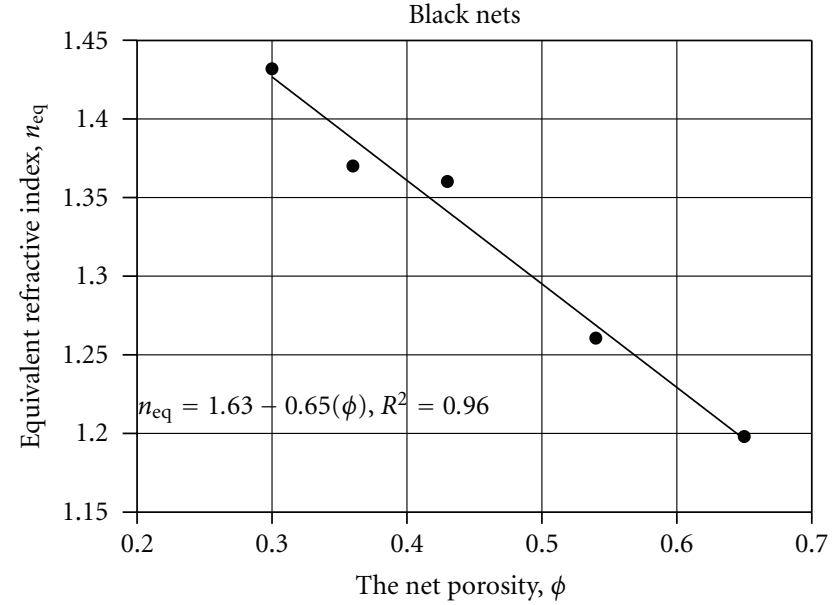

(a)

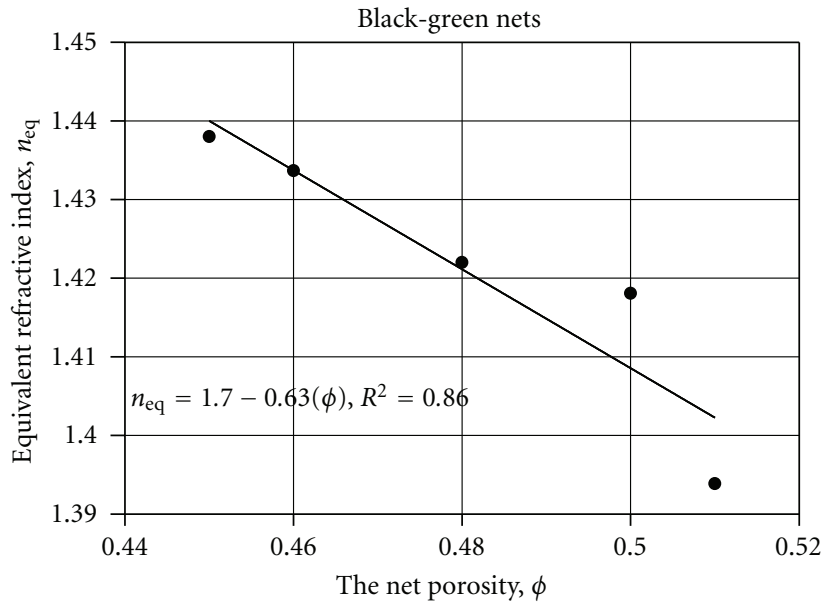

(b)

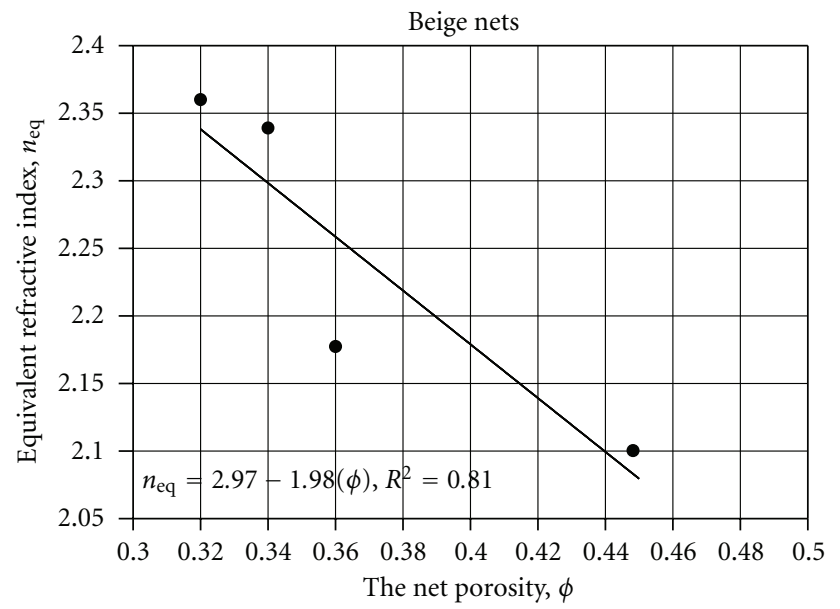

(c)

FIGURE 3: The equivalent refractive index $\left(n_{\mathrm{eq}}\right)$ as affected by the porosity of the tested nets: (a) is for the black group, (b) for the black-green group, and (c) for the beige group.

resubstituting $\tau_{\theta}^{*}$ and $\rho_{\theta}^{*}$ into (1) to obtain $\tau_{r}$ and $\rho_{r}$ for the desired direction. The diffuse solar radiation incident over a surface can be treated as a direct beam radiation with an incidence angle $(\theta)$ of $60^{\circ}[12]$. Thus the directional transmittance and reflectance of a net with respect to the global solar radiation $\left(\tau_{g}\right.$ and $\left.\rho_{g}\right)$ are defined by

$$
\begin{gathered}
\tau_{g}=\tau_{r, 60^{\circ}} I_{D}+\left(1-I_{D}\right) \tau_{r}, \\
\rho_{g}=\rho_{r, 60^{\circ}} I_{D}+\left(1-I_{D}\right) \rho_{r},
\end{gathered}
$$

where $I_{D}$ is the diffuse index estimated as $\left(D_{i} / S_{i}\right)$ at the desired direction $\theta$.

2.3. Measuring the Required Parameters. For determining the transmittance and reflectance of the net to direct beam solar radiation $\left(\tau_{r}\right.$ and $\left.\rho_{r}\right)$ to be used as input parameters to (1) and (2), the experiment was conducted on the roof of the building of the Agricultural Research and Experiment Station, Agriculture Engineering Department, King Saud University (Riyadh, Saudi Arabia, 46 $47^{\prime}$ E, longitude and $24^{\circ} 39^{\prime} \mathrm{N}$, latitude). The measurements were conducted at around solar noon on clear, sunny days from September 10 to September 25, 2011. One pyranometer, CMP3 (Kipp \& Zonen B.V. Inc., USA), and one albedometer, CMA-11 (Kipp \& Zonen B.V. Inc., USA) were used. Each net sample was tacked onto a black painted wooden frame $(50 \mathrm{~cm} \times$ $60 \mathrm{~cm} \times 30 \mathrm{~cm})$. The frame was oriented toward the sun, so that incidence angle of the solar beam radiation $(\theta)$ was nearly zero. The transmitted global solar radiation $\left(S_{t}\right)$ was measured below the net surface using the pyranometer. The incident and reflected global solar radiation $\left(S_{i}\right.$ and $\left.S_{r}\right)$ were measured above the net sample using the albedometer. This procedure was repeated while shading the frame with an opaque plate to measure the diffuse solar radiation components below $\left(D_{t}\right)$ and above $\left(D_{i}, D_{r}\right)$ the net sample. The measured parameters were recorded every 10 seconds, averaged over one-minute intervals and saved in a data logger (LI-1400, 9 channels, LI-COR, Inc.). For each parameter, five values were measured at normal incidence, and the average value was obtained. The sensors had been calibrated before 


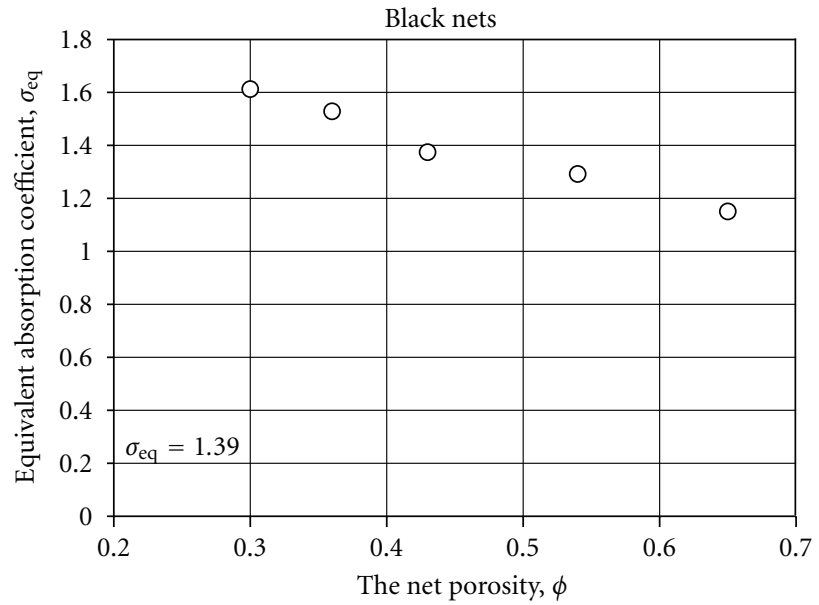

(a)

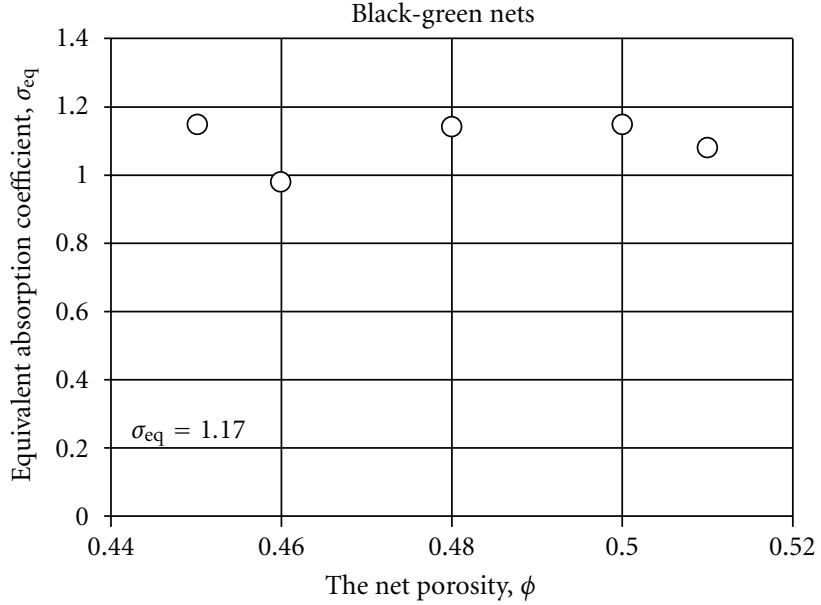

(b)

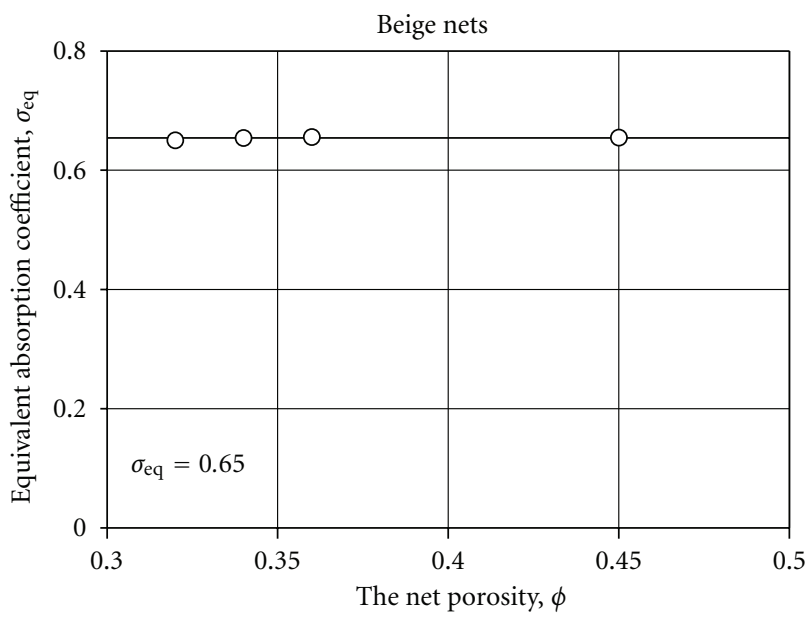

(c)

Figure 4: The equivalent absorption coefficient $\left(\sigma_{\mathrm{eq}}\right)$ as affected by the porosity of the tested nets: (a) is for the black group, (b) for the black-green group, and (c) for the beige group.

use by the supplier. The components of the direct beam radiation $\left(B_{i}, B_{t}\right.$, and $\left.B_{r}\right)$ were determined as the difference between the global and diffuse radiation components. Thus at normal incidence, the net transmittance to direct beam radiation $\left(\tau_{r}\right)$ was estimated as $\left(B_{t} / B_{i}\right)$ and the net reflectance to direct beam radiation $\left(\rho_{r}\right)$ was estimated as $\left(B_{r} / B_{i}\right)$.

\section{Results and Discussion}

For each net sample, the measured values of $\tau_{r}$ and $\rho_{r}$ at normal incidence were substituted consequently into (2) and (1) to obtain the values of $\tau^{*}$ and $\rho^{*}$. Substituting the values of $\tau^{*}$ and $\rho^{*}$ into (3) and (4) gives the equivalent optical constants $\left(n_{\mathrm{eq}}\right.$ and $\left.\sigma_{\mathrm{eq}}\right)$ of the selected net. The optical constants of a net did not depend on the direction of the incident beam radiation; therefore they are used to estimate the directional radiative properties of the net. The values of $n_{\text {eq }}$ as affected by the net porosities $(\phi)$ are illustrated in Figures 3(a), 3(b), and 3(c), for the black nets group, the black-green nets group and the beige nets group, respectively.
The data in Figures 3(a), 3(b), and 3(c) show that $n_{\text {eq }}$ decreases when $\phi$ increases and correlations between $n_{\mathrm{eq}}$ and $\phi$ could be obtained with reasonable $R^{2}$ values in the following form:

$$
\begin{gathered}
n_{\mathrm{eq}}=1.63-0.65(\phi), \quad\left(R^{2}=0.96\right) \text { for black nets, } \quad(8 \\
n_{\mathrm{eq}}=1.7-0.63(\phi), \quad\left(R^{2}=0.86\right) \text { for black-green nets, }
\end{gathered}
$$

$$
n_{\mathrm{eq}}=2.97-1.98(\phi), \quad\left(R^{2}=0.81\right) \text { for beige nets. }
$$

Ideally, if the value of $\phi$ in (8), (9), and (10) increased to one (no net), then the values of $n_{\mathrm{eq}}$ should equal to one (i.e., the refractive index of air). However, there are residuals of +0.02 in (8), -0.07 in (9), and +0.01 in (10) that should be added to $n_{\text {eq }}$ estimated form (8)-(10). These equations also show that value of $n_{\text {eq }}$ increases with increasing brightness of the net color, which means more reflection is expected. The nets with the brightest color in this study (the beige nets) showed 


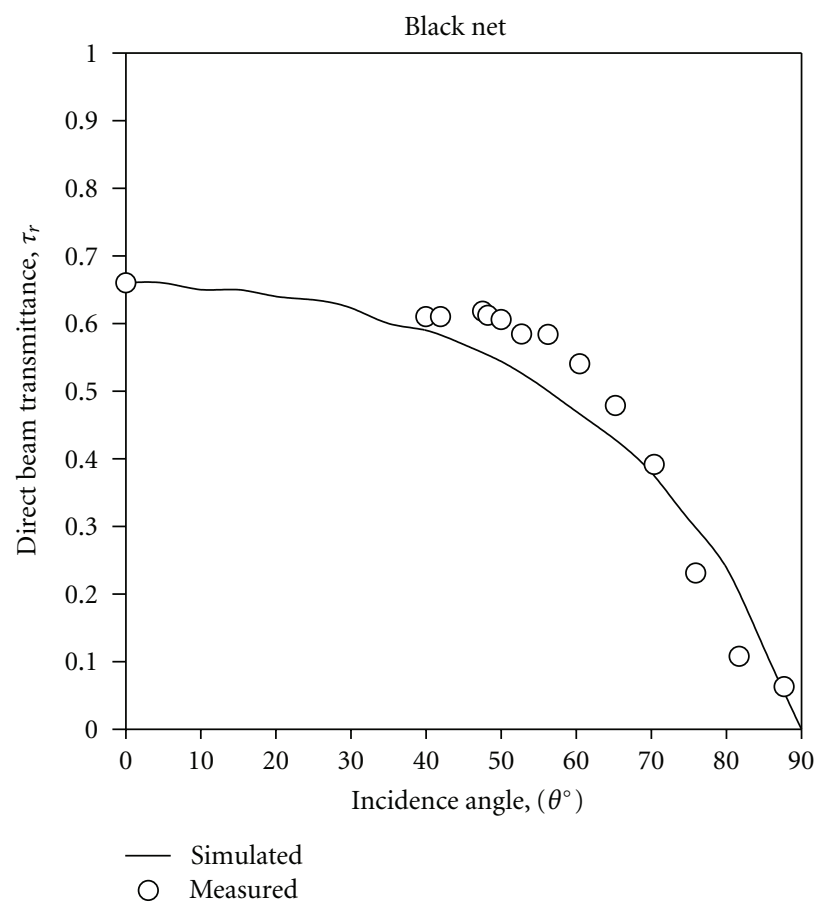

(a)

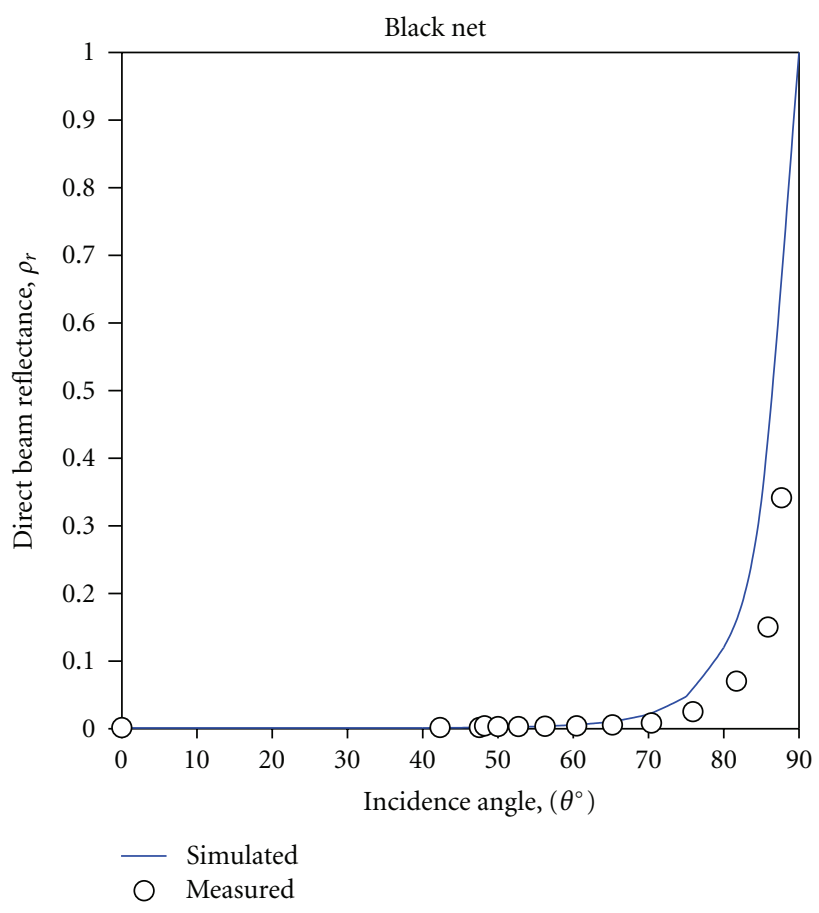

(b)

Figure 5: Comparison between the measured [8] and simulated values of (a) the direct beam transmittance $\left(\tau_{r}\right)$ and $(\mathrm{b})$ the direct beam reflectance $\left(\rho_{r}\right)$ for the black net.

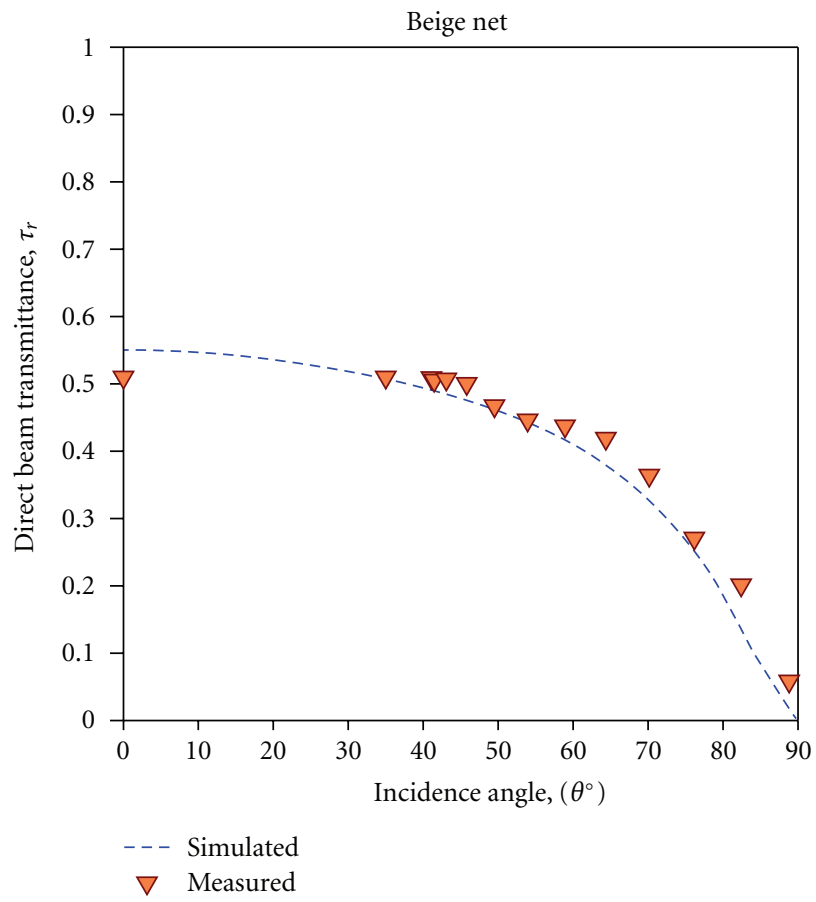

(a)

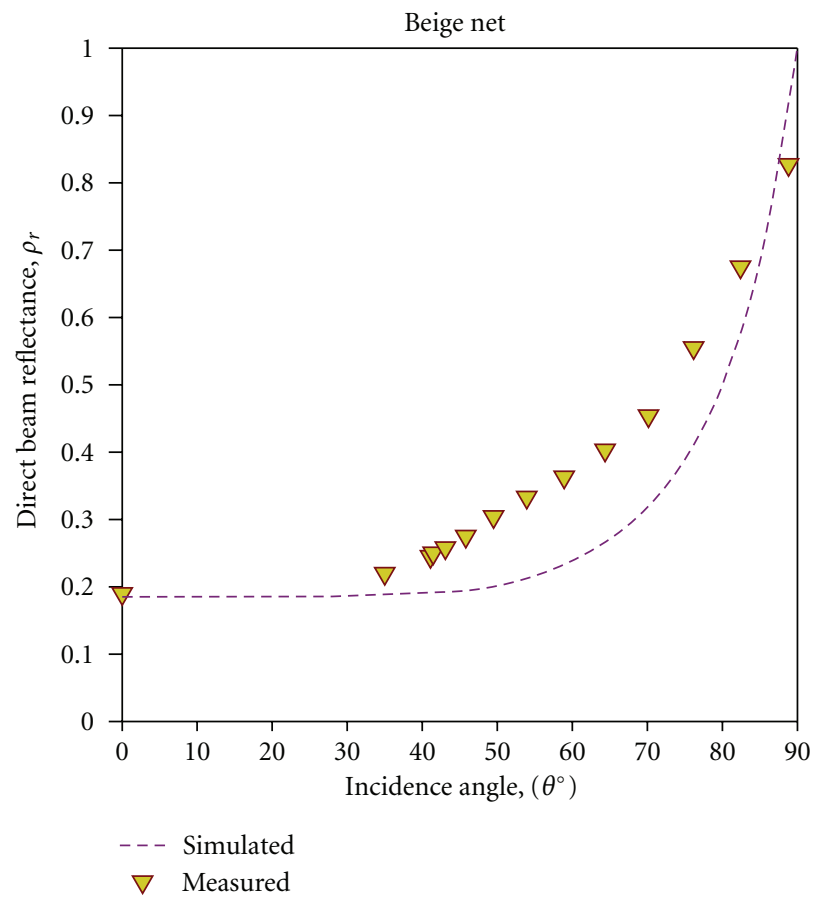

(b)

FIGURE 6: Comparison between the measured [8] and simulated values of (a) the direct beam transmittance $\left(\tau_{r}\right)$ and (b) the direct beam reflectance $\left(\rho_{r}\right)$ for the beige net. 


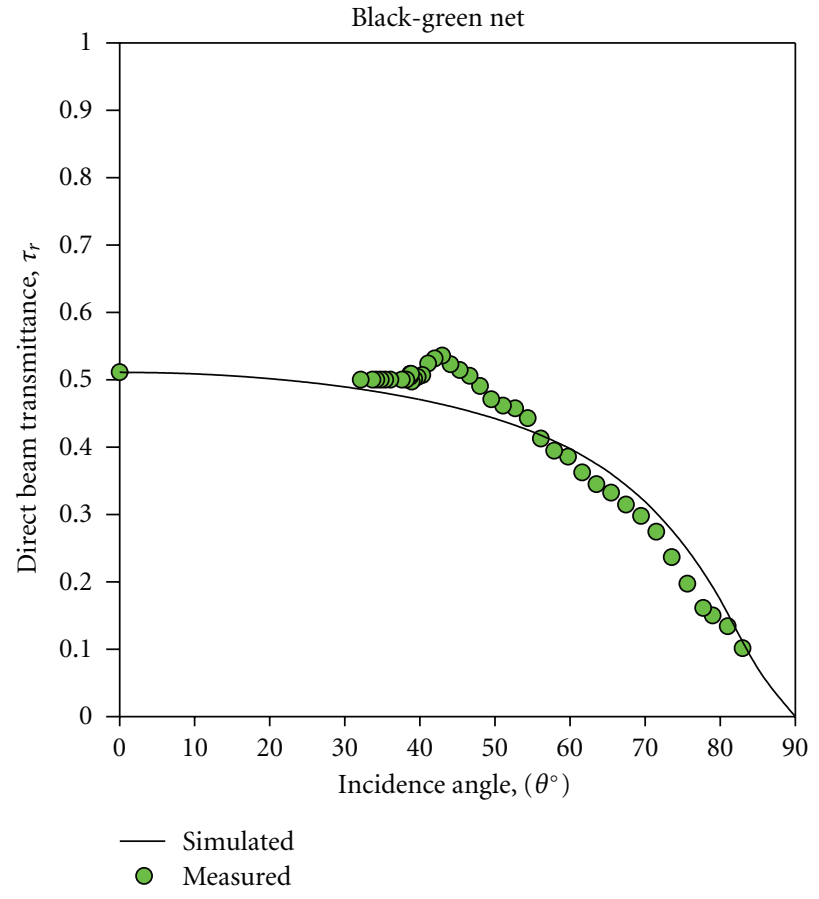

(a)

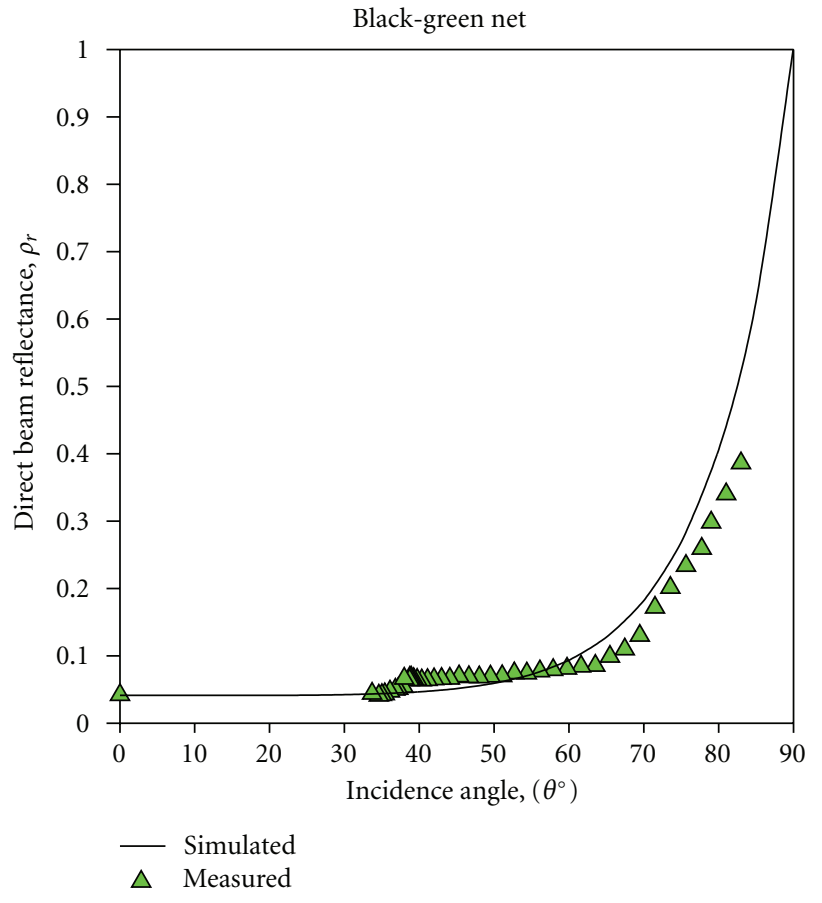

(b)

Figure 7: Comparison between the measured [8] and simulated values of (a) the direct beam transmittance $\left(\tau_{r}\right)$ and $(\mathrm{b})$ direct beam reflectance $\left(\rho_{r}\right)$ for the black-green net.

the highest value of $n_{\mathrm{eq}}$ whereas nets with the darkest color (the black nets) showed the lowest $n_{\text {eq }}$.

The effects of the net porosity $\phi$ on the value of $\sigma_{\text {eq }}$ are illustrated in Figures 4(a), 4(b), and 4(c) for the black group, for the black-green group, and for the beige group, respectively. According to (4) and (6) and in analogy with homogeneous translucent materials, the value of $\sigma_{\text {eq }}$ should be constant for each group of nets. And the value of $\tau_{\theta}^{*}$ in (6) depends on the porosity, $\phi$, of the net and on the direction, $\theta$, of the incident beam radiation. The data in Figure 4(c) for the beige nets group satisfy the hypothesis that $\sigma_{\mathrm{eq}}$ is constant for each group of nets. However, the values of $\sigma_{\text {eq }}$ for the black and black-green groups (Figures 4(a) and 4(b)) did not satisfy the hypothesis exactly. This was mainly due to the low number of data points as a result of the low availability of net groups in the local markets. Therefore, an average value for each net group was used.

\section{Validation of the Model}

The main purpose of the validation is to check the capability of $n_{\mathrm{eq}}$ and $\sigma_{\mathrm{eq}}$, estimated using the present model, to calculate the directional radiative properties of nets under natural solar radiation conditions. In a previous study [8] we measured the direct beam transmittance $\left(\tau_{r}\right)$ and reflectance $\left(\rho_{r}\right)$ for a black net $(\phi=0.65)$, for a beige net $(\phi=0.12)$, and for a black-green net $(\phi=0.47)$ at different incident angles $(\theta)$ of the direct beam solar radiation. Values of $\tau_{r}$ and $\rho_{r}$ at normal incidence were measured for the three nets (see Section 2.2). The simulated values of $\tau_{r}$ and $\rho_{r}$ using the present model at different $\theta$ comparing with the measured values of $\tau_{r}$ and $\rho_{r}$ are illustrated, respectively, in Figures 5(a) and 5(b) for the black net, in Figures 6(a) and 6(b) for the beige net, and in Figures 7(a) and 7(b) for the black-green net. Reasonable agreement was shown between the simulated and the measured $\tau_{r}$ and $\rho_{r}$ for the black, beige, and blackgreen nets.

Figures 5(a), 5(b), 6(a), 6(b), 7(a), and 7(b) do not show measured values of $\tau_{r}$ and $\rho_{r}$ at low values of incidence angle $\left(0^{\circ}<\theta<33^{\circ}\right)$ because of the latitude and the time of the year at which the experiments were carried out (the lowest value of $\theta$ was estimated to be about $33^{\circ}$ at solar noon). In addition, when $\theta$ was near or equal to $90^{\circ}$, the beam radiation incident on the thread surfaces reflects downwards. This increased $\tau_{r}$ to a value higher than zero and reduced $\rho_{r}$ to a value much lower than one.

\section{Conclusions}

A modeling approach for determining the equivalent optical constants $\left(n_{\mathrm{eq}}\right.$ and $\left.\sigma_{\mathrm{eq}}\right)$ of plastic nets was described and validated. Three groups of nets (black, beige, and blackgreen) were tested. For each group, an equation for $n_{\mathrm{eq}}$ as a function of the net porosity was derived, and an average value for $\sigma_{\text {eq }}$ was determined. Using values of $n_{\text {eq }}$ and $\sigma_{\text {eq }}$, the directional solar radiative properties of the net can be calculated without the need of measurements which are expensive and time consumed. The resulting properties are equivalent for the whole net as a semitransparent material, not for the net material itself. The present model was 
validated by comparing the measured radiative properties of three of the nets, at different incident angle of solar beam radiation, with those calculated using the present model. The calculated radiative properties agreed with the measured values. Further research is needed to investigate $n_{\mathrm{eq}}$ and $\sigma_{\mathrm{eq}}$ for other nets communities with different colors (e.g., a blue group, an orange group, a white group, a green group, etc.).

\section{Nomenclature}

$B_{i}$ : Direct beam solar radiation flux incident on the net surface $\left(\mathrm{W} \mathrm{m}^{-2}\right)$

$B_{r}$ : Direct beam solar radiation flux reflected from the net $\left(\mathrm{W} \mathrm{m}^{-2}\right)$

$B_{t}$ : Direct beam solar radiation flux transmitted through the net $\left(\mathrm{W} \mathrm{m}^{-2}\right)$

$D_{i}$ : Diffuse radiation flux incident on the net surface $\left(\mathrm{W} \mathrm{m}^{-2}\right)$

$D_{r}$ : Diffuse radiation flux reflected from the net surface $\left(\mathrm{W} \mathrm{m}^{-2}\right)$

$D_{t}$ : Diffuse radiation flux transmitted through the net $\left(\mathrm{W} \mathrm{m}^{-2}\right)$

$I_{D}$ : The diffuse index (i.e., ratio of diffuse to global solar radiation flux)

$n_{\text {eq }}$ : Equivalent refractive index of the net (dimensionless)

$S_{i}$ : Global solar radiation flux incident on the net surface $\left(\mathrm{W} \mathrm{m}^{-2}\right)$

$S_{r}$ : Global solar radiation flux reflected from the net surface $\left(\mathrm{W} \mathrm{m}^{-2}\right)$

$S_{t}$ : Global solar radiation flux transmitted through the net $\left(\mathrm{W} \mathrm{m}^{-2}\right)$

$\Phi$ : The net porosity (i.e., the empty area per unit area)

$\theta: \quad$ Incident angle of solar beam radiation (degree)

$\theta_{r}$ : Equivalent refracted angle of solar beam radiation (degree)

$\rho_{g}:$ Reflectance of the net to global solar radiation (dimensionless)

$\rho_{r}:$ Reflectance of the net to direct beam solar radiation (dimensionless)

$\rho^{*}$ : Interface reflectance between the net surface and air (dimensionless)

$\rho_{\theta}^{*}$ : Directional interface reflectance between the net surface and air (dimensionless)

$\sigma_{\mathrm{eq}}$ : Equivalent absorption coefficient of the net (dimensionless)

$\tau_{g}$ : Transmittance of the net to global solar radiation (dimensionless)

$\tau_{r}$ : Transmittance of the net to direct beam solar radiation (dimensionless)

$\tau^{*}$ : Transmittance of the net due to absorption only in the net threads (dimensionless).

\section{Acknowledgments}

This work was financially supported by the National Plan for Sciences and Technology (NPST) Program, King Saud
University, Project no. 09-ENE912-02. The authors express thank to M. R. Shady for technical assistance during the experiments.

\section{References}

[1] S. Castellano, G. M. Scarascia, G. Russo et al., "Plastic nets in agriculture: a general review of types and applications," Applied Engineering in Agriculture, vol. 24, pp. 799-808, 2008.

[2] S. Castellano, G. Russo, and G. Scarascia Mugnozza, "The influence of construction parameters on radiometric performances of agricultural nets," Acta Horticulturae, vol. 718, pp. 283-290, 2006.

[3] D. Briassoulis, A. Mistriotis, and D. Eleftherakis, "Mechanical behaviour and properties of agricultural nets-part II: analysis of the performance of the main categories of agricultural nets," Polymer Testing, vol. 26, no. 8, pp. 970-984, 2007.

[4] D. Briassoulis, A. Mistriotis, and D. Eleftherakis, "Mechanical behaviour and properties of agricultural nets-part I: testing methods for agricultural nets," Polymer Testing, vol. 26, no. 6, pp. 822-832, 2007.

[5] A. M. Abdel-Ghany and I. M. Al-Helal, "Characterization of solar radiation transmission through plastic shading nets," Solar Energy Materials and Solar Cells, vol. 94, no. 8, pp. 13711378, 2010.

[6] A. M. Abdel-Ghany and I. M. Al-Helal, "Analysis of solar radiation transfer: a method to estimate the porosity of a plastic shading net," Energy Conversion and Management, vol. 52, no. 3, pp. 1755-1762, 2011.

[7] S. Hemming, G. L. A. M. Swinkels, S. Castellano, G. Russo, and G. M. Scarascia, "Numerical model to estimate the radiometric performance of net covered structures (AGRONETS)," in Proceedings of the Agricultural and Biosystems Engineering for a Sustainable World (AgEng '08), Crete, Greece, June 2008.

[8] I. M. Al-Helal and A. M. Abdel-Ghany, "Measuring and evaluating solar radiative properties of plastic shading nets," Solar Energy Materials and Solar Cells, vol. 95, no. 2, pp. 677-683, 2011.

[9] I. M. Al-Helal and A. M. Abdel-Ghany, "Responses of plastic shading nets to global and diffuse PAR transfer: optical properties and evaluation," Wageningen Journal of Life Sciences, vol. 57, no. 2, pp. 125-132, 2010.

[10] A. M. Abdel-Ghany, T. Kozai, and C. Chun, "Evaluation of selected greenhouse covers for use in regions with a hot climate," Japanese Journal of Tropical Agriculture, vol. 45, pp. 242-250, 2001.

[11] L. He, T. H. Short, and X. Yang, "Solar radiation transmittance of a double-walled acrylic pellet-insulated greenhouse," Transactions of the American Society of Agricultural Engineers, vol. 34, no. 6, pp. 2559-2563, 1991.

[12] J. A. Duffie and W. A. Beckman, Solar Engineering of Thermal Processes, John Wiley \& Sons, New York, NY, USA, 2nd edition, 1991.

[13] M. M. Elsayed, I. S. Taha, and J. A. Sabbagh, Design of Solar Thermal Systems, Scientific Publishing Center, King Abdulaziz University, Jeddah, Saudi Arabia, 1st edition, 1994.

[14] S. S. Soulayman, Z. Nassif, and A. Harfoush, "Transmittance, reflectance and absorptance of multi-plate planar window," Renewable Energy, vol. 1, no. 2, pp. 211-217, 1991.

[15] A. M. Abdel-Ghany, T. Kozai, C. Kubota, and I. S. Taha, "Investigation of the spectral optical properties of the liquid radiation filters for using in the greenhouse application," Japan Journal of Agriculture Meteorology, vol. 57, pp. 11-19, 2001. 

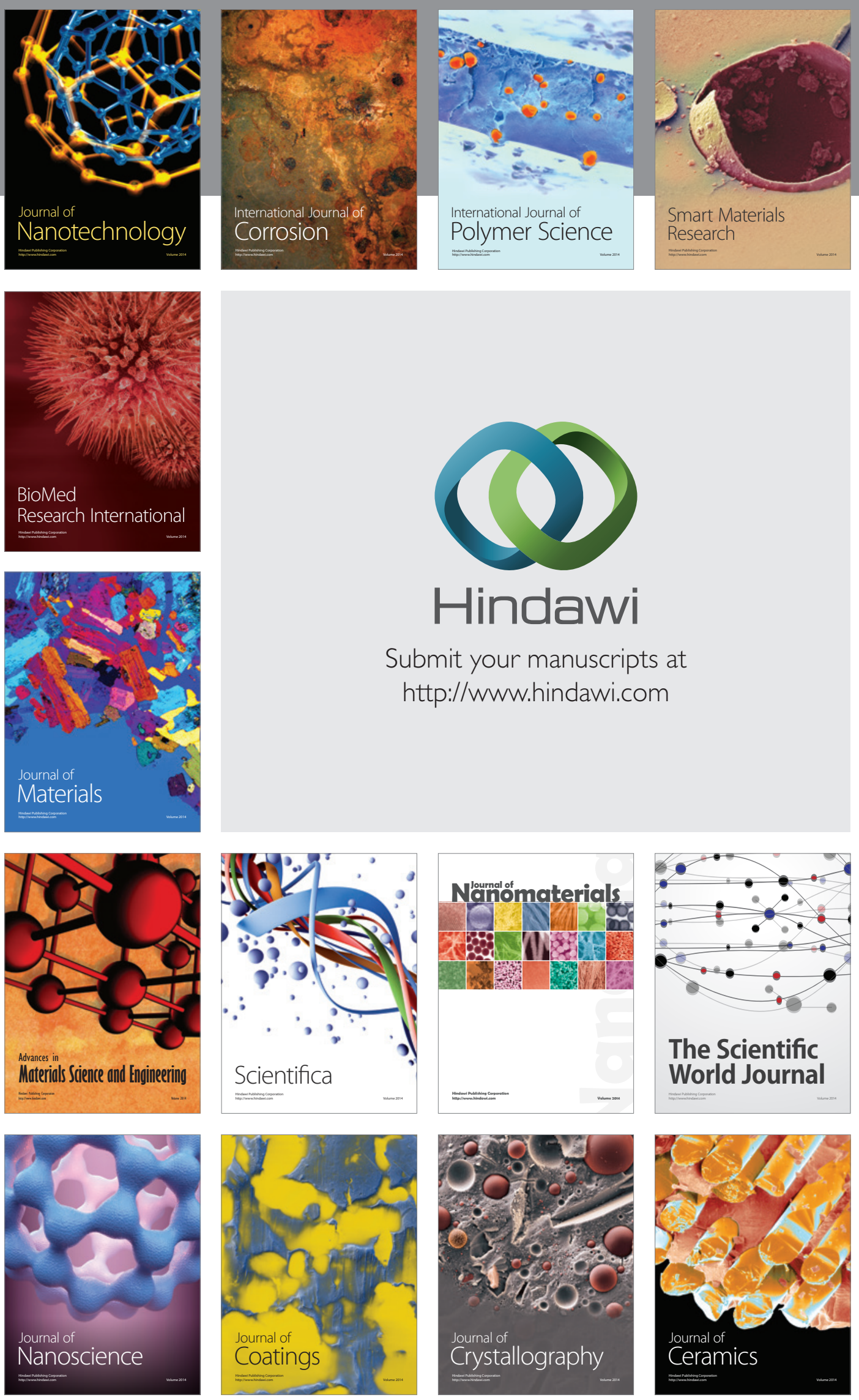

The Scientific World Journal

Submit your manuscripts at

http://www.hindawi.com

\section{World Journal}

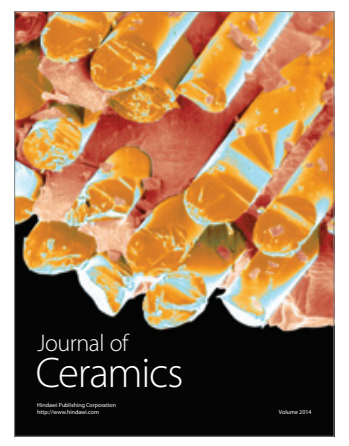

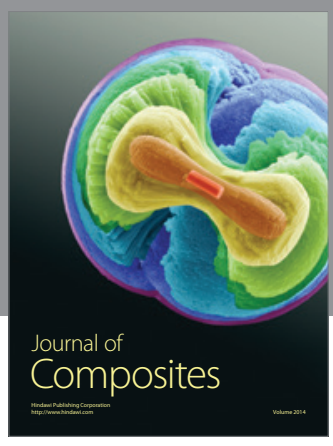
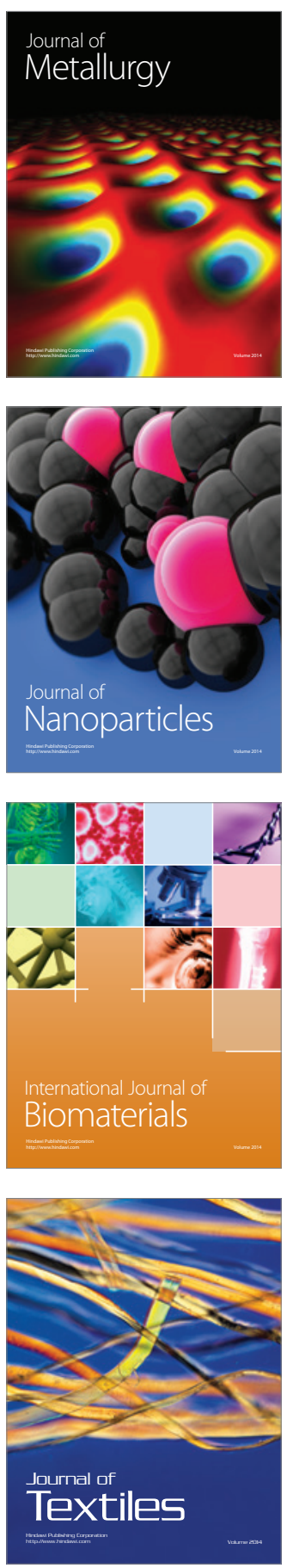